\title{
Smart phone use and sleep disturbances, depression and anxiety in adolescents
}

\author{
P. Kulkarni V. ${ }^{1}$, Kumar L. ${ }^{2}$, Reddi Naidu L. ${ }^{3}$ \\ DOI: https://doi.org/10.17511/ijphr.2019.i2.03 \\ $\mathbf{1}$ Ved P. Kulkarni, Professor, Department of Community Medicine, Maharajah's Institute of Medical Sciences, Vizianagaram, Andhra Pradesh, \\ India. \\ 2* L. Santosh Kumar, Assistant Professor, Department of Pediatrics, Maharajah's Institute of Medical Sciences, Vizianagaram, Andhra \\ Pradesh, India. \\ 3 L. Venkata Reddi Naidu, Post Graduate, Department of Community Medicine, Maharajah's Institute of Medical Sciences, Vizianagaram, \\ Andhra Pradesh, India.
}

Background: Keeping in mind about the rapid advancement and extensive use of mobile phones, and their immense effect on communication and interactions, it is important to study potential negative health effects of mobile phone exposure especially among adolescents. Material \& Methods: A cross-sectional study was conducted to assess smartphone use and sleep disturbances, depression in adolescents among 469 adoloscents studying in Government Polythechnic college, Vizianagaram using a structured questionnaire containing details of demographics, educational status, purpose of using the smart phone etc, PSQI and DASS 21 for sleep quality, depression stress and anxiety. Results: The prevalence of smart phone addiction among participants was $29.63 \%$ (30.08\% in males and $29.21 \%$ in females). Factors associated with smartphone addiction in male students were use of gaming apps and internet surfing. Significant factors for female students were use ofuse of social networking services and communication services (Calling and texting). Depression, anxiety and quality of sleep are significantly associated with smart phone addiction. Conclusion: Smartphone addiction was common among the polyechnic students investigated. This study identified associations between smartphone usage, psycho-behavioral factors, and smartphone addiction, and the associations differed between males and females. These results suggest the need for interventions to reduce smartphone addiction among degree students. The results of this study suggest that adolescents might benefit from education regarding sleep hygiene and the risks of electronic media use at night.

Keywords: Smartphone, Adolescent, Addiction, Depression, Anxiety

Corresponding Author

L. Santosh Kumar, Assistant Professor, Department

of Pediatrics, Maharajah's Institute of Medical Sciences, Vizianagaram, Andhra Pradesh, India. Email: vedkulkarni@rediffmail.com
How to Cite this Article

Kulkarni VP, Kumar LS, Naidu LVR. Smart phone use and sleep disturbances, depression and anxiety in adolescents. Public Health Rev Int J Public Health Res. 2019;6(2):61-67.

Available From

https://publichealth.medresearch.in/index.php/ijphr/ article/view/101
To Browse

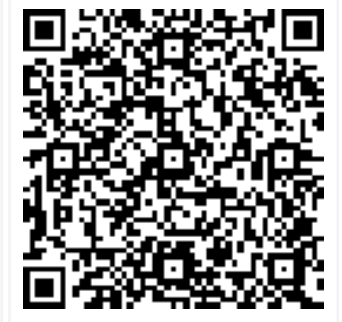

Manuscript Received 2019-03-05

Conflict of Interest No
Review Round 1 2019-03-15

Funding

$\mathrm{Nil}$
Review Round 2 2019-03-22

Ethical Approval Yes
Review Round 3

Accepted 2019-03-25

Plagiarism X-checker $8 \%$

(c) 2019 by Ved P. Kulkarni, L. Santosh Kumar, L. Venkata Reddi Naidu and Published by Siddharth Health Research and Social Welfare Society. This is an Open Access article licensed under a Creative Commons Attribution 4.0 International License https://creativecommons.org/licenses/by/4.0/ unported [CC BY 4.0]. 


\section{Introduction}

A smartphone is "a mobile phone that performs many of the functions of a computer, typically has internet access, and an operating system capable of running downloaded applications" [1]. Communication channels have been so phenomenally upgraded that communicating a person with thousands of miles apart is simply a game of seconds now using messenger, WhatsApp, voice call etc.

Young people expand their opportunities for making social relationships using Smartphone [2]. It has become one of the most important academic and recreational tools for adolescents and young adults [3]. With the greater availability of the Smartphone, excessive Smartphone use for adolescents and young adults can Indian Journal of Science and Technology, lead to many problems such as low academic achievement [4], interpersonaldistress [5] and mal-adjustment of school life [6], sleeping disturbance [7], depression [8], psychological distress [9] and Smart phone addiction [10].

\section{Objectives}

01. To study the extent of smartphone addiction among adolescent students.

02. To determine whether overuse of smartphone is associated with anxiety and depression in adolescent students.

03. To determine whether overuse of smartphone is associated with quality of sleep in adolescent students.

04. To give suitable recommendations based on the study

\section{Methodology}

Study design: Cross sectional Analytical study.

Study area: Maharajaha Ananda Gajapathi Raju Government Polytechnic College, Phool Baugh, Vizianagaram.

Sample size: Ananda Gajapathi Raju's government polytechnic college, Vizianagaram. By taking the prevalence of smartphone addiction as $17 \%$ from a previous study conducted by Severin haug, Raquel pazcastroet al. on Smartphone use and smartphone addiction among young people, the sample size is calculated as below.

A sample size of 469 students is calculated out of
Total 1141 students in the age group 16 to 19 years studying in various branches of Maharajah

Sample size was calculated by using the formula:

$\mathrm{N}=\mathrm{Z} 2 \mathrm{pq} / \mathrm{I} 2$

Where $p=0.17$ (prevalence of smartphoneaddiction $17 \%)$

$\mathrm{Q}=1-\mathrm{p}=0.83$

$L=20 \%$ of $p=0.034$

If $a=0.05$ then $Z 0.05=1.96$

Therefore, Sample size $=469$

Study instrument: Structured questionnaire was administered.

Semistructured proforma: Semi structured proforma that contained details of demographics, educational status, purpose of using the smart phone, money spent per month, place of access, the time of day when accessed the most and the average duration of use per day. Data was collected from those using smart phone for at least last 3 months.

Smart phone addiction scale (SAS) Short version: Smartphone addiction was measured using the Smartphone Addiction Scale short version (SAS-SV). The SAS-SV is a validated scale that contains 10 items rated on a dimensional scale (1 "strongly disagree" to 6 "strongly agree") [11].

The total score ranges from 10 to 60 , with the highest score representing the maximum presence of "smartphone addiction" in the past year. The original SAS-SV showed content and concurrent validity and internal consistency (Cronbach's alpha: 0.91 ). Smartphone addiction cut-off values of $\geq 31$ and $\geq 33$ for male and female participants, respectively, were applied as suggested by Kwon et al. [11].

Pittsburgh sleep quality index: Sleep quality was assessed using Pittsburgh Sleep Quality Index (PSQI) [12], which is a widely used 19-item selfreport questionnaire that measures subjective sleep quality. The 19 items are grouped into scores with seven components: subjective sleep quality, sleep latency, sleep duration, sleep efficiency, sleep disturbances, use of sleep medication, and daytime dysfunction.

The scores of these components are added to a global PSQI score with a range of 0 to 21 , with 
Higher scores indicating worse sleep quality. PSQI scores above 5 were taken as abnormal.

\section{Depression anxiety stress score 21 [DASS 21]:}

21 item self-report questionnaires designed to assess the severity of core symptoms of Depression, Anxiety and Stress. It can be administered by the respondents themselves or by another person.

It is crucial that each question is answered. It is rated on a four-point Likert scale, each item is scored from 0 to 3 . The sum of the relevant 7 items multiplied by 2 for each scale constitutes the participants' scores for each of Depression, Anxiety and Stress [13].

Study Period: A period of 3 months (1st Julyto 30th September, 2018)

\section{Inclusion criteria}

01. Maharajah Ananda Gajapathi Raju Government Polytechnic College Students of both genders in the age group of 16 to 19 years.

02. Adolescent students with Smartphone usage of 90 minutes and more in a day.

\section{Exclusion criteria}

01. Adolescent students with Smartphone usage of less than 90 minutes and more in a day.

Data analysis: Data was collected by using questionnaire and interviews to evaluate the percentage of smartphone usage for various purposes among the respondents. Collected data was entered in MS Excel and analyzed using SPSS version 21. Results are shown in the form of percentages, tables and figures.

Ethical clearance: Ethical clearance was obtained from Institutional Ethical Committee, MIMS

\section{Results}

In the current study among the total of 469 polytechnic students it was observed that $48.18 \%$ of them were malesand the remaining $51.82 \%$ werefemales. The students were aged between 1619 years with a mean age of $17.72 \pm 1.43$ years.

Table-1: Age and Gender wise distribution.

\begin{tabular}{|l|l|l|l|}
\hline \multicolumn{1}{|c|}{ Age } & \multicolumn{1}{|c|}{ Male (\%) } & \multicolumn{1}{c|}{ Female (\%) } & \multicolumn{1}{c|}{ Total (\%) } \\
\hline$<17$ & $98(43.36)$ & $107(44.04)$ & $205(43.71)$ \\
\hline$>17$ & $128(56.64)$ & $136(55.96)$ & $264(56.29)$ \\
\hline Total & 226 & 243 & 469 \\
\hline
\end{tabular}

From the above table it is clear that majority $(56.29 \%)$ of the study subjects were in the age
Group of more than Seventeen years and the remaining $43.71 \%$ belong to equal to or less than 17.

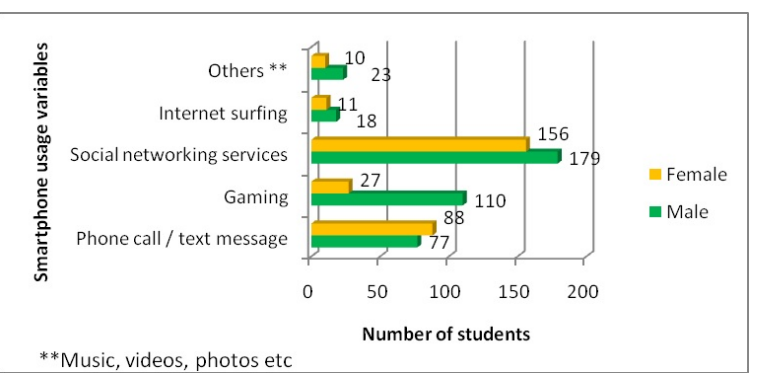

Fig-1 : Showing Smartphone usage among study subjects

Figure 1 show that usage social networking services was found to be higher i.e., $71.4 \%$ ( $79.2 \%$ males and $64.2 \%$ females) next to Phone call / texting $(35.2 \%)$ and gaming $(29.2 \%)$ and in these both male and female were found to be using smartphone for phone calling / texting in equal proportions but when it comes to gaming major proportion (48.6\%) were males and only $11.2 \%$ of females.

Table-2: Smartphone addiction among polytechnic students.

\begin{tabular}{|l|l|l|l|}
\hline \multicolumn{1}{|c|}{ Addiction } & \multicolumn{1}{c|}{ Male (\%) } & \multicolumn{1}{c|}{ Female (\%) } & \multicolumn{1}{c|}{ Total (\%) } \\
\hline Present & $68(30.08)$ & $71(29.21)$ & $139(29.63)$ \\
\hline Absent & $158(69.92)$ & $172(70.79)$ & $330(70.37)$ \\
\hline Total & 226 & 243 & 469 \\
\hline
\end{tabular}

Chisquare value $=0.425, \mathrm{df}=1, \mathrm{p}=0.837$

Smartphone addiction was found to be almost in similar proportions on comparison between male and female i.e., $30.08 \%$ of males have addiction towards smartphone and among females $29.21 \%$ have smartphone addiction.

Table-3: Showing distribution of Depression, anxiety and Sleep quality among the study subjects.

\begin{tabular}{|c|c|c|c|c|}
\hline & & $\begin{array}{c}\text { Male }(\%) N= \\
226\end{array}$ & $\mid \begin{array}{c}\text { Female }(\%) \mathrm{N} \\
243\end{array}$ & $\begin{array}{c}\text { Total }(\%) \mathrm{N}= \\
469\end{array}$ \\
\hline \multirow[t]{3}{*}{ Depression } & Positive & 73 (32.3) & $55(22.6)$ & $128(27.29)$ \\
\hline & Negative & $153(67.7)$ & $188(77.4)$ & 341 (72.71) \\
\hline & \multicolumn{4}{|c|}{$* * \mathrm{p}$ value $=0.019$} \\
\hline \multirow[t]{3}{*}{ Anxiety } & Positive & $29(12.8)$ & 17 (6.99) & $46(9.8)$ \\
\hline & Negative & $197(87.2)$ & $226(93.01)$ & $423(90.2)$ \\
\hline & \multicolumn{4}{|c|}{${ }^{* *} \mathrm{p}$ value $=0.034$} \\
\hline \multirow{3}{*}{$\begin{array}{l}\text { Sleep } \\
\text { Quality }\end{array}$} & Good & $151(66.8)$ & $149(61.3)$ & 300 (63.9) \\
\hline & Bad & 75 (33.2) & 94 (38.7) & 169 (36.1) \\
\hline & \multicolumn{4}{|c|}{$* * p$ value $=0.215$} \\
\hline
\end{tabular}


Table 3 presents that Depression and anxiety were significantly associatedin males on comparison with
Females. Where as poor quality of sleep was predominant in females than in male students.

Table-4: Gender wise association of Depression, Anxiety and sleep quality with smart phone addiction.

\begin{tabular}{|c|c|c|c|c|c|c|c|c|c|}
\hline \multicolumn{2}{|c|}{ Variables } & \multicolumn{8}{|c|}{ Smartphone addiction } \\
\hline & & \multicolumn{4}{|c|}{ Male } & \multicolumn{4}{|c|}{ Female } \\
\hline & & Positive & Negative & OR & P value & Positive & Negative & OR & $P$ value \\
\hline \multirow[t]{2}{*}{ Depression } & Present & 30 & 43 & \multirow[t]{2}{*}{$2.86(1.53-5.34)$} & \multirow[t]{2}{*}{$<0.001$} & 22 & 33 & \multirow[t]{2}{*}{$1.89(1.01-3.55)$} & \multirow[t]{2}{*}{0.047} \\
\hline & Absent & 28 & 115 & & & 49 & 139 & & \\
\hline \multirow[t]{2}{*}{ Anxiety } & Present & 15 & 14 & \multirow[t]{2}{*}{$2.83(1.28-6.2)$} & \multirow[t]{2}{*}{0.009} & 10 & 7 & \multirow[t]{2}{*}{$3.86(1.41-10.60)$} & \multirow[t]{2}{*}{0.008} \\
\hline & Absent & 54 & 143 & & & 61 & 165 & & \\
\hline \multirow[t]{2}{*}{ Quality of sleep } & Good & 39 & 112 & \multirow[t]{2}{*}{$0.55(0.30-0.99)$} & \multirow[t]{2}{*}{0.048} & 33 & 116 & \multirow[t]{2}{*}{$0.42(0.24-0.74)$} & \multirow[t]{2}{*}{0.002} \\
\hline & Bad & 29 & 46 & & & 38 & 56 & & \\
\hline
\end{tabular}

Table 4 represents the univariate analyses of potential factors (Depression, Anxiety and Sleep quality) related to smartphone addiction. Poor sleep quality, depression, and anxiety were significantly associated with smartphone addiction in both males and females.

\section{Discussion}

In the present study done on polytechnic students of Government polytechnic college students, majority $(51.82 \%)$ were females and the remaining were male students. Similar setup was found in the study done by Baifen Chen et al[29] where $51.7 \%$ of the study participants were females.

The prevalence of smartphone addiction among the study subjects in the current study was found to be $29.63 \%$, measured with the help SAS, which was higher than that in previous studies on college students using the same instrumentin Korea $[14,15]$ and they found that proportion of students who are at risk of having smartphone addiction ranged from $21 \%$ to $27 \%$. The prevalence of smartphone addiction in a sample of 293 undergraduate students from a university of J city, Korea was $14.7 \%$ [16]. Research was carried out on smartphone addiction and its effect on various activities on undergraduate students, done with different scales in a study conducted in China showed that the prevalence of smartphone associated problems in undergraduates was $21.3 \%$ [17].

A prevalence of $16.9 \%$ among 1519 participants was reported by a set of researchers from Switzerland [18]. Another study reported a much higher prevalence of $33.3 \%$ prevalence level among
Adolescentsin a college at Ajmer, Rajasthan [19], while a $27.2 \%$ prevalence has been linked to highrisk smartphone users among university students in Riyadh [20]. These discrepancies could be due to the different instruments and classification methods used at the time of data collection, and also differences among the participants and geographical setup in the different studies. Yet, the high prevalence rate identified in the current study is an indication of possible public health concern posed by smartphone over use among the adolescent students studied. The results of this study on prevalence of smartphone addiction showed no significant gender differences, where smartphone addiction was $30.08 \%$ in males and $29.21 \%$ in females with a probability value $>0.05$. Similar results as of current study were reported in some previous research $[16,21]$.

Nevertheless, some studies have reported that female participants have a higher prevalence of smartphone addiction than males [14,15]. A study conducted in Turkey on Medical studentsby Kadir reported that the mean SAS score of female students was significantly higher than that of male students [22]. Similarly, higher prevalence of $19.4 \%$ was observed in females and is only $14.1 \%$ in males[18]. The use ofsmartphones differed between the two gendersas male students were more likely to play games, watch videos, and listen to music, whereas female students were more tending to use the mobile phone communication functions (calling and texting) and social networking services were observed in the current study. Cell phone (smartphone) is a source of social contact for females in which messaging and social networks play major role, while for males, a more branched 
Out type of usage was observed, involving text messages, phone calling, and gaming applications [23].

A study carried out by Roberts et al. [24] on cell phone activities and addiction among male and female college students, reported that the most challenging applications are voice calls, text messages, and social networks in relation to smartphone overuse. This inconsistent prevalence of smartphone addiction in males and females needs further research. Some evidence was available stating that smartphone overuse was associated with various psychological and behavioral problems, such as depression, anxiety, and sleep disturbance. However, the impending etiology was unclear.A significantly higher proportion of high smartphone users had depression and anxiety than low smartphone users $(p=0.005)$. There was no direct effect of high smartphone use on sleep quality but high smartphone use and poor sleep quality were also related to depression[22]. It has been found that depressed individuals use their smartphones as a coping strategy to deal with their negative emotions [25]. Excessive smartphone use at night could keep one up late leading to sleep difficulties, thus influencing stress and depression [26]. Use of computers, cell-phones and televisions at higher doses was associated with delayed sleep/wake schedules and wake lag, potentially impairing health and educational outcomes [27]. The relationship between excessive use of mobile phone use and lifestyle, social support, insomnia, and depression was found to have significant association [28].

The findings of the present study are consistent with some and contrary with other previous studies with respect to the over-use of smartphones and its relationship to depression, anxiety, and poor sleep quality. In the present study, some smartphone applications and psycho-behavioral factors were associated with smartphone addiction. Playing smartphone games was a predictor of smartphone addiction for males, whereas use of multimedia and social networking applications were predictors for females. Although the gender difference may only reflect preferences for smartphone apps, the findings indicate the need for gender-targeted prevention and intervention strategies to reduce smartphone addiction.

Regarding psycho-behavioral factors, depression, poor sleep quality and anxiety were significantly associated with smartphone addiction in both males and females, it is probable that depression was
More prevalent in male students than female students in the present study. Psychosocial factors such asgender differences in stress coping, genderspecific expectations that males should have a good economical settlement may be the reasons behind male preponderance towards depression.

\section{Conclusion}

- Wide spread smartphone addiction among polytechnic college students, which suggests that smartphone addiction would become a public health issue.

- Playing games on smartphones predicted addiction for male students, whereas uses of multimedia and social networking applications were predictors for females.

- Smartphone addiction may result in psychological and behavioral problems, such as depression, anxiety, and poor sleep quality, and females who scored at the addiction level were more likely to be depressed than males.

- Considering the gender differences in smartphone addiction targeted prevention and intervention strategies based on a multicomponent strategy to reduce these behavioral problems are recommended.

- Few healthcare providers, however, have received in-depth training in sleepand may not inquire about sleep as a contributor to largerhealth issues in their patients.

- Smart phones undoubtedly enhance connectivity and information for students. However, it is vital to curtail its usage to reduce depression anxiety and stress in order to improve the mental health status of students.

- Considering the gender differences in smartphone addiction highlighted by the present study, targeted prevention and intervention strategies based on a multi-component strategy to reduce this behavioral problem are recommended.

\section{Limitations}

01 . A sample of 469 cannot be generalized to whole of adolescent's population.

02. The data was cross-sectional, which limits the ability to draw underlying inferences, particularly those concerning direction of association between smartphone addiction and risk factors of psychological behavior. 
03. The participants were all polytechinic college students; this may limit the generalization of the present results to other at-risk groups.

04. Functional impairments such as blurred vision and pain in the wrists or necks of participants were not investigated here.

\section{Reference}

01. Oxford Dictionaries. [cited August 2016].

[Article] [Crossref]

02. Igarashi T, Takai J, Yoshida T. Gender differences insocial network development via mobile phone text messages- a longitudinal study. Journal of Social and Personal Relationships. 2005;Oct;22 (5)691-713.

[Crossref]

03. Hong FY, Chiu SI, Huang DH. A model of the relationship between psychological characteristics, mobile phone addiction and use of mobile phones by Taiwanese university female students. Computers in Human Behavior. 2012;Nov;28(6)2152-9.

[Crossref]

04. Roberts JA, Pullig C, Manolis C. I need my Smart-phone- A hierarchical model of personality and cell-phone addiction. Personality and Individual Difference. 2015; Jun;79;13-9.

[Crossref]

05. Takao M, Takahashi S, Kitamura M. Addictive personality and problematic mobile phone use. Cyberpsychol Behav. 2009;Oct;12(5)501-7. doi: [Article] [Crossref]

06. Choi HS, Lee HK, Ha JC. The influence of Smartphone addiction on mental health, campus life and personal relations- Focusing on $\mathrm{K}$ university students. Journal of the Korean Data and Information Science Society. 2012;Sep;23(5)1005-15.

[Crossref]

07. Ahn SY, Kim YJ. The influence of Smartphone use and stress on quality of sleep among nursing students. Indian Journal of Science and Technology. 2015;Dec;8(35)1-6.

[Crossref]

08. Thomée S, Härenstam A, Hagberg M. Mobile phone useand stress, sleep disturbances, and symptoms of depression among youngadults- a prospective cohort study. BMC Public Health. $2011 ; \operatorname{Jan}-31 ; 11 ; 66$.

doi: [Article] [Crossref]
09. Thomee S, Eklof M, Gustafsson E, Nilsson R, Hagberg M. Prevalence of perceived stress, symptoms of depression and sleep disturbances on relation to information and communication technology use among young adults- An explorative prospective study. Computers in Human Behavior. 2007; May;23(3)1300-21. [Crossref]

10. Bian M, Leung L. Linking loneliness, shyness, Smartphone addiction symptom and patterns of Smartphone use to social capital. Social Science Computer Review. 2015 Feb;33(1)61-79. [Crossref]

11. Kwon M, Kim D, Cho $H$, Yang $S$. The Smartphone addiction scale- development and validation of a short version for adolescents. PLoS One. 2013;8 (12): e83558.

[Crossref]

12. Buysse DJ, Reynolds CF 3rd, Monk TH, et al. The Pittsburgh Sleep Quality Index- a new instrument for psychiatric practice and research. Psychiatry Res. 1989;May;28(2)193-213. [Crossref]

13. Lovibond SH, Lovibond PF. Manual for the Depression Anxiety Stress Scales" (2nd ed), Sydney- Psychology Foundation. (Available from The Psychology Foundation, Room 1005 Mathews Building, University of New South Wales, NSW 2052, Australia). 1995.

[Crossref]

14. Kim SM. Smartphone use level of nursing college students the relationship between communication competence, social avoidance and distress. [Unpublished master's thesis]Daejeon, Korea- Chungnam National University. 2014.

[Crossref]

15. Jeon HS, Jang SO. A study on the influence of depression and stress on Smartphone addiction among university students- Focused on moderating effect of gender. Korean Journal of Youth Studies. 2014;Aug;21(8)103-29.

[Crossref]

16. Kwon YS and Paek KS. The influence of smartphone addiction on depression and communication competence among college students. Indian journal of science and technology. 2016;Nov;9(41).

[Crossref] 
17. Long J, Liu TQ, Liao $\mathrm{YH}$, et al. Prevalence and correlates of problematic smartphone use in a large random sample of Chinese undergraduates. BMC Psychiatry. 2016 Nov $17 ; 16(1) 408$.

doi: [Article] [Crossref]

18. Severin Haug, Raquel Paz Castro, Min Kwon, Andreas Filler, Tobias Kowatsch, Michael P. Smartphone use and smartphone addiction among young people in Switzerland. Journal of Behavioral Addictions. 2015;4(4)299-307. [Crossref]

19. Ruchi Soni, Ritesh Upadhyay, Mahendra Jain. Prevalence of smartphone addiction, sleep quality and associated behaviour problems in adolescents. International journal of research in medical sciences. 2016;Feb;5(2)515-519.

[Crossref]

20. Alosaimi FD, Alyahya $H$, Alshahwan $H$, et al. Smartphone addiction among university students in Riyadh, Saudi Arabia. Saudi Med J. 2016; Jun;37(6)675-83.

doi: [Article] [Crossref]

21. Kwon M, Lee JY, Won WY, et al. Development and validation of a smartphone addiction scale (SAS). PLoS One. 2013;8(2)e56936.

doi: [Article] [Crossref]

22. Demirci K, Akgönül $M$, Akpinar $A$, et al. Relationship of smartphone use severity with sleep quality, depression, and anxiety in university students. J Behav Addict. 2015 Jun;4(2)85-92.

doi: [Article] [Crossref]

23. De-Sola Gutiérrez J, Rodríguez de Fonseca F, Rubio G. Cell-Phone Addiction- A Review. Front Psychiatry. 2016;Oct 24;7;175.

eCollection 2016. doi: [Article] [Crossref]

24. Roberts JA, Yaya LH, Manolis C. The invisible addiction- cell-phone activities and addiction among male and female college students. J Behav Addict. 2014;Dec;3(4)254-65. doi: [Article] [Crossref]

25. Kim J, Seo M, David P. Alleviating depression only to become problematic mobile phone users- can face-to-face communication be the antidote?. Comput Hum Behav. 2015;51(PA)440-7.

[Crossref]
26. Lemola S, Perkinson-Gloor N, Brand S, et al. Adolescents' electronic media use at night, sleep disturbance, and depressive symptoms in the smartphone age. J Youth Adolesc. 2015 Feb;44(2)405-18.

doi: 10.1007/s10964-014-0176-x. Epub 2014 Sep 10 [Crossref]

27. Gamble AL, D'Rozario AL, Bartlett DJ, et al. Adolescent sleep patterns and night-time technology use- results of the Australian Broadcasting Corporation's Big Sleep Survey. PLoS One. 2014;INov;12;9(11)e111700.

doi: 10.1371/ journal. pone.0111700. eCollection 2014 [Crossref]

28. Tamura Haruka, Tomoko Nishida, Akiyo Tsuji, Hisataka Sakakibara. Association between Excessive Use of Mobile Phone and Insomnia and Depression among Japanese Adolescents. Int J Environ Res Public Health. 2017;14;701. [Crossref]

29. Baifeng Chen, Fei Liu, Shushu Ding, Xia Ying, Lele Wang and Yufeng Wen. Gender differences in factors associated with smartphone addictiona cross-sectional study among medical college students. BMC Psychiatry. 2017;17;341. [Crossref] 